Original Article

\title{
The Relationship of the Grading of Lumbar Spinal Stenosis and Pain Improvement after Caudal Epidural Steroid Injection
}

\author{
Waqas Noor Chughtai, Muhammad Adeel Razzaque, Tanveer Ahmad, Sumera Nighat \\ Bashir Ahmad, Muhammad Azhar Javed
}

Bakhtawar Amin Medical College and Hospital, Multan, Pakistan

\begin{abstract}
Objective: This study aimed to determine the relation of severity of lumbar spinal stenosis and pain improvement after caudal epidural injection.

Material and Methods: 70 patients of neurogenic claudication were included from July 2019 to June 2020. MRI lumbosacral spine was done of all patients to categorize the degree of spinal stenosis on T2-W axial. All patients were given caudal epidural steroid injection as a day case procedure. Follow-up was done at $3 \& 8$ weeks and pain improvement was assessed by using Ronald satisfaction score.
\end{abstract}

Results: Mean age was $37.9 \pm 7.8$ years. $48.6 \%$ patients were male and $51.6 \%$ were female. The improvement was observed in 28 patients (40\%) at 3 weeks and in 46 patients $(65.7 \%)$ at 8 weeks. There was no statistically significant relationship between lumbar

spinal stenosis and pain improvements at 3 weeks ( $p$ value 0.30 ) and 8 weeks ( $p$ value 0.32 ).

Conclusion: The grade of lumbar spinal stenosis has no significant effect on pain improvement after caudal epidural steroid injection.

Keywords: LSS (Lumbar spinal stenosis), caudal epidural steroid injection (ESI), neurogenic claudication, MRI (Magnetic resonance imaging), T2W (T2 weighted) images.

Corresponding Author: Waqas Noor

Bakhtawar Amin Medical College and Hospital, Multan,

Pakistan

Email: drwawas220@gmail.com

Date of Submission: 15-10-2020

Date of Revision: 6-11-2020

Date of Online Publishing: 25-12-2020

Date of Print: 30-12-2020

DOI: $10.36552 /$ pjns.v24i4.461

\section{INTRODUCTION}

Degenerative lumbar spinal stenosis (LSS) is a common cause of low back pain and disability in our population. ${ }^{1}$ Spinal stenosis is narrowing of the spinal canal by bone and soft tissues that causes compression of the central spinal canal, lateral recesses and intervertebral foramina. As far as pathophysiology is concerned, there are degenerative changes in the lumbar spine like disc degeneration, spondylosis, facet joint 
degeneration, ligamentum flavum hypertrophy, osteophyte formation and degenerative scoliosis. ${ }^{2}$ Neurogenic claudication is the cardinal feature of Lumbar spine stenosis in which there is buttocks and bilateral lower limb pain initiated by walking, standing, and walking downhill. It is typically relieved by sitting and bending forward.

The patient will present with low back pain, unilateral or bilateral radiculopathy sensory loss, weakness and loss of reflexes in myotome distribution. ${ }^{3}$ Magnetic resonance imaging (MRI) is an excellent investigation to determine the cause of spinal stenosis. In MRI the status of disc bulges, disc generation, ligamentum flavum hypertrophy, facet joint hypertrophy, central canal size, lateral recess encroachment, neural foraminal size and nerve root entrapment can be assessed. ${ }^{4}$ Despite the prevalence of disease, the treatment of LSS remained controversial. The treatment options include conservative measure such as non-steroidal anti-inflammatory drugs (NSAIDS), activity modification, and physiotherapy, as well as more invasive treatments such as epidural steroid injections (ESI) and surgery. ${ }^{5}$

Epidural steroid injections (ESIs) are suitable treatment option for lumbar spinal stenosis radicular symptoms. Epidural steroid injections prevent the inflammatory cascade, act as a nerve membrane stabilizer and block the nociceptive type C-fibers. ${ }^{6}$ The ideal injection delivers the medicine to the exact site of inflammation, the affected nerve root, and the neural plexus. Interlaminar, transformational, and caudal are the 3 commonly used routes to enter the epidural space. ${ }^{7}$ Contrast injection is usually injected before the administration of medicine. This will determine the distribution of injection and avoid injection into vascular structures or the intrathecal space. Surgery for lumbar spinal stenosis is generally done when conservative treatments have failed or if the stenosis substantially impairs the patients' lifestyle. ${ }^{8}$
The rationale and objective of our study is to determine the relation of lumbar spinal canal stenosis and pain improvement after caudal epidural injection. The literature about this topic is inconclusive and there is no local data available on this topic.

\section{MATERIAL AND METHODS}

\section{Study Setting and Design}

A Quasi experimental study was conducted at Bakhtawar Amin Hospital Multan after getting an approval institutional ethical review board. 70 patients of lumbar spinal stenosis were included in the study for duration of one year from July 2019 to June 2020. Informed consent was taken from every patient.

\section{Sampling Technique and Sample Size}

The sampling technique was simple random probability sampling. The sample size was calculated using the software $G$ Power version 3.1.9.4. Considering the values of effect size as 0.3 , alpha as 0.05 and power of the test as $80 \%$, a sample size of 64 was calculated. However, we took a sample size of 70 .

\section{Inclusion Criteria}

Patients having low back pain with radicular pain, neurogenic claudication having central canal stenosis on axial images of MRI lumbosacral spine were included.

\section{Exclusion Criteria}

Patients having symptoms of low back pain without symptoms of leg pain, patients having foraminal and extraforaminal stenosis, spondylolisthesis, patients having previous back surgery, neurological deficits, comorbids and extremes of age were excluded. 


\section{Data Collection}

The diagnosis of LSS was done on clinical symptoms, neurological examination and radiological investigation including $\mathrm{MRI}$ of lumbosacral spine.

1.5 tesla MRI of lumbosacral spine was done in all patients in the study. ${ }^{9}$ Grading of lumbosacral spine stenosis was based on degree of separation of the cauda equina on T2weighted axial images (grade 0: no lumbar stenosis with no obliteration of anterior CSF space, grade I: mild lumbar stenosis with all cauda equine separable, grade II: moderate lumbar stenosis with cauda equina aggregated and grade III: severe lumbar stenosis with none of the cauda equina separated). Radiologist confirmed the grading of spinal stenosis. ${ }^{10}$

Caudal epidural injection was given to all patients. ${ }^{11}$ The procedure was done in Operation Theater under fluoroscopic guidance. Patient was placed prone on operation table. The target area identified in fluoroscope and infiltrated with local $2 \%$ xylocaine injection. ${ }^{12} 22 \mathrm{G}$ spinal needle was used to enter the epidural space via sacral hiatus. The epidural space was confirmed by giving omnipaque contrast and checked under fluoroscope. ${ }^{13}$ Total volume of $10 \mathrm{ml}$ was injected containing Injection depomedrol $80 \mathrm{mg}$, injection bupivacaine and $0.9 \%$ normal saline. ${ }^{14}$ The procedure was done as a day case procedure and patient was discharged $4-5$ hours after injection.

\section{Follow-up}

Patients follow-up was done at 3 and 8 weeks post injection and outcome was assessed by using Roland satisfaction score: (1: little pain; 2: moderate pain; 3 : bad pain; 4: very bad pain; 5 : almost unbearable pain). ${ }^{15}$ The pain outcome score was further categorized into two groups (improved: 0 - 2, not improved: $3-5$ ) to determine the correlation between pain reduction and lumbar spine stenosis grade and gender.

\section{Data Analysis}

SPSS version 23 was used for data analysis. Demographic analysis included the assessment of age, gender and degree of stenosis. Pain improvement after epidural injection was analyzed by frequency and percentages. The relationship between degree of spinal stenosis, gender and pain improvement at 3 and 8 weeks was assessed by chi - square test. $P$ value of $<0.05$ was taken as significant.

\section{RESULTS}

\section{Age Incidence}

There were 70 patients in the study with lumbar spinal stenosis with age ranging from $24-55$ years. The mean age was $37.9 \pm 7.8$ years.

\section{Gender Incidence}

Male patients were 34 (48.6\%) and female were 36 (51.6\%).

\section{Severity of Lumbar Stenosis}

Mild stenosis were present in 16 (22.9\%), moderate stenosis in 30 (42.9\%) and severe stenosis were present in 24 (34.3\%).

\section{Improvement in Pain}

Table 1 shows the statistics of pain improvement at 3 and 8 weeks post injection. Table 2 shows the categorization of pain improvement.

Table 1: Number of Patients mentioned for Pain improvement after epidural injection.

\begin{tabular}{|ccc|} 
Pain Improvement & At $\mathbf{3}$ Weeks & At 8 Weeks \\
0 & $1(1.4 \%)$ & $4(5.7 \%)$ \\
1 & $7(10 \%)$ & $10(14.3 \%)$ \\
2 & $20(28.6 \%)$ & $32(46.7 \%)$ \\
3 & $29(41.4 \%)$ & $22(31.4 \%)$ \\
4 & $10(14.3 \%)$ & $2(2.9 \%)$ \\
5 & $3(4.3 \%)$ & 0 \\
\hline
\end{tabular}




\section{Relationship of LSS and Pain Improvement}

The relationship between lumbar spinal stenosis grade and pain improvement was checked by chi square test. There was no statistically significant relation between lumbar spinal stenosis and pain improvement at 3 weeks ( $p$ value 0.30 ) and 08 weeks ( $p$ value 0.32 ) (Table 3).

\section{Relationship of Gender and Pain Improvement}

The relationship between gender of patient and pain improvement at 3 and 8 weeks was checked by chi square test. There was no statistically significant relation between gender and pain improvement at 3 weeks ( $p$ value 0.09 ) and 08 weeks ( $p$ value 0.4 ).
Table 3: Relationship of pain improvement and grade of stenosis at 3 and 8 weeks follow-up.

\begin{tabular}{|lccccc|} 
Grade of & \multicolumn{2}{c}{3 Weeks } & \multicolumn{2}{c}{8 Weeks } \\
Stenosis & Improved & $\begin{array}{c}\text { Not } \\
\text { Improved }\end{array}$ & Improved & $\begin{array}{c}\text { Not } \\
\text { Improved }\end{array}$ \\
Mild (I) & 9 & 7 & 13 & 3 \\
Moderate (II) & 10 & 20 & 18 & 12 \\
Severe ( III) & 9 & 15 & 15 & 9 \\
P value & & 0.30 & & \multicolumn{2}{c}{0.32} \\
\hline
\end{tabular}

Table 4: Relationship between pain improvement and gender 3 and 8 weeks follow-up.

\begin{tabular}{lccccc|} 
Gender & \multicolumn{2}{c}{3 Weeks } & \multicolumn{2}{c}{8 Weeks } \\
Male & Improved & $\begin{array}{c}\text { Not } \\
\text { Improved }\end{array}$ & Improved & $\begin{array}{c}\text { Not } \\
\text { Improved }\end{array}$ \\
Female & 17 & 17 & 24 & 10 \\
P value & 11 & 29 & 22 & 14 \\
\hline
\end{tabular}

\section{DISCUSSION}

The results of our study showed that there is no significant relation between the degree of spinal stenosis and the pain improvement after caudal epidural injection. The patients having mild spinal stenosis did not improve and patients of severe stenosis improved after caudal epidural injection. Patients having variable degree of stenosis on MRI were given epidural injection but the pain improvement was not corresponding to degree of stenosis.

We hypothesized that the cause of spinal stenosis is multifactorial. There is mechanical component including degenerated discs, facet hypertrophy and ligamentum flavum hypertrophy and chemical component. Chemical inflammation is an important factor in the development of symptoms of spinal stenosis. Various cytokines and inflammatory mediators were released in spinal stenosis and they cause the symptoms of neurogenic claudication. By giving caudal epidural injection including both lidocaine and steroid, we address the inflammatory component. Steroids will suppress inflammation and lidocaine with anaesthetize the nerve. ${ }^{6}$ Imaging measures on MRI are usually do not correspond to degree of symptoms. Patients have severe stenosis have mild symptoms and patients have mild to moderate stenosis have severe symptoms. That is why we used epidural injections to suppress inflammatory component of spinal stenosis. But the results do not correspond to our hypothesis. Patients having severe spinal stenosis improved with caudal injections more than patients of mild 
to moderate stenosis showing that inflammatory component of spinal stenosis is not the only factor determining the symptoms of spinal stenosis. $^{12}$

One factor may be that axial images on MRI may not be fully reflective of spine canal dimensions and it may reflect the inconsistent response to caudal epidural injection and pain improvement. Another underlying factor is the use of static images to grade LSS. This will result in the inconsistent relationship between symptoms and the degree of lumbar spinal canal stenosis. There is wide variability between patients having LSS and symptoms. Some patients have severe stenosis but have mild symptoms and vice versa. The symptoms of LSS changes widely over time. ${ }^{4}$

Prior studies were done to determine the relationship between spinal canal dimensions and response to ESI and the results were inconsistent. Park et al did study on 47 patients. He did MRI scans of all patients to categorize the stenosis and gave CT guided epidural injections. He assessed the pain improvement by 5 point pain scale. He found no relation between severity of spinal stenosis and epidural steroid injections. ${ }^{15}$ Perez et al did double blind RCT on patients which were given epidural lidocaine alone or with steroid. He measured the size of lumbar spine by qualitative (CT scan) and quantitative (MRI scans). Pain improvement was assessed by Roland-Morris Disability Questionnaire and the leg pain numeric rating scale at 3 weeks following injection. His results showed that imaging measures were not associated with clinical pain improvement. ${ }^{4}$ Kapural et al did retrospective study. He included the lumbar spinal levels and degree of stenosis in study. He gave series of epidural injections. His results showed that the patients having multilevel stenosis improved well with series of epidural injections as compared to patients having single level stenosis. As far as degree of stenosis is concerned, this is not related to the pain improvement after series of epidural injections. ${ }^{16}$

\section{CONCLUSION}

The grade of lumbar spinal stenosis have no significant effect on pain improvement after caudal epidural steroid injection.

\section{LIMITATIONS}

The limitations of our study were we have not done CT scans of patients to determine the size of spinal canal. We have not taken lumbar spinal levels involved in spinal stenosis in our study. We have not given spinal level specific injection which could give better improvement in pain relief. CT guided epidural injections can also be given to target the specific spinal level. Outcome was assessed by VAS only but functional outcome or psychological variables were not taken into account.

\section{REFERENCES}

1. Andresen AK, Ernst $C$, Andersen M. Lumbar spinal stenosis. Ugeskr Laeger, 2016; 178 (41): V04160245.

2. Lafian AM, Torralba KD. Lumbar Spinal Stenosis in Older Adults. Rheum Dis Clin North Am. 2018; 44 (3): 501-512.

3. Deer T, Sayed D, Michels J, Josephson Y, Li S, Calodney AK. A Review of Lumbar Spinal Stenosis with Intermittent Neurogenic Claudication: Disease and Diagnosis. Pain Med. 2019; 20 (Suppl. 2): S32S44.

4. Perez FA, Quinet S, Jarvik JG, Nguyen QT, Aghayev E, Jitjai $D$ et.al. Lumbar Spinal Stenosis Severity by CT or MRI Does Not Predict Response to Epidural Corticosteroid versus Lidocaine Injections. AJNR Am J Neuroradiol. 2019; 40 (5): 908-915.

5. Ammendolia C, Stuber KJ, Rok E, Rampersaud R, Kennedy CA, Pennick $V$, et.al. Non-operative treatment for lumbar spinal stenosis with neurogenic claudication. Cochrane Database Syst Rev. 2013; 30; (8): CD010712, 1-60.

6. Manchikanti L, Knezevic NN, Boswell MV, Kaye $A D$, Hirsch JA. Epidural Injections for Lumbar Radiculopathy and Spinal Stenosis: A Comparative Systematic Review and Meta-Analysis. Pain 
Physician, 2016; 19 (3): E365-410.

7. Lattes SM, Weiss A, Found E, Zimmerman B, Gao Y, Comparable effectiveness of caudal vs. transforaminal epidural steroid injections. lowa Orthop J. 2009; 29: 91-6.

8. Zaina F, Tomkins-Lane C, Carragee E, Negrini S. Surgical versus non-surgical treatment for lumbar spinal stenosis. Cochrane Database Syst Rev. 2016 Jan 29; 2016 (1): CD010264.

9. Majidi $H$, Shafizad $M$, Niksolat $F$, Mahmudi $M$, Ehteshami S, Poorali $M$, et.al. Relationship between Magnetic Resonance Imaging Findings and Clinical Symptoms in Patients with Suspected Lumbar Spinal Canal Stenosis: a Case-control Study. Acta Inform Med. 2019; 27 (4): 229-233.

10. Lee GY, Lee JW, Choi HS, Oh KJ, Kang HS. A new grading system of lumbar central canal stenosis on MRI: an easy and reliable method. Skeletal Radiol. 2011; 40 (8): 1033-9.

11. Kao SC, Lin CS. Caudal Epidural Block: An Updated Review of Anatomy and Techniques. Biomed Res Int. 2017; 2017: 9217145.
12. Sim WS, Park HJ, Kwon JH, Oh MS, Jung HJ, Cho MK, Lee JY. Fluoroscopic evaluation of the influence of needle gauge on epidural spread in caudal block. Medicine (Baltimore), 2019; 98 (22): e15896.

13. Manchikanti L, Cash KA, Pampati V, McManus CD, Damron KS. Evaluation of fluoroscopically guided caudal epidural injections. Pain Physician, 2004; 7 (1): 81-92.

14. Owlia MB, Salimzadeh A, Alishiri G, Haghighi A. Comparison of two doses of corticosteroid in epidural steroid injection for lumbar radicular pain. Singapore Med J. 2007; 48 (3): 241-5.

15. Park $\mathrm{CH}$, Lee $\mathrm{SH}$. Correlation between severity of lumbar spinal stenosis and lumbar epidural steroid injection. Pain Med. 2014; 15 (4): 556-61.

16. Kapural L, Mekhail N, Bena J, McLain R, Tetzlaff J, Kapural $M$, et.al. Value of the magnetic resonance imaging in patients with painful lumbar spinal stenosis (LSS) undergoing lumbar epidural steroid injections. Clin J Pain. 2007; 23 (7): 571-5.

\section{Additional Information}

Disclosures: Authors report no conflict of interest.

Ethical Review Board Approval: The study was conformed to the ethical review board requirements.

Human Subjects: Consent was obtained by all patients/participants in this study.

\section{Conflicts of Interest:}

In compliance with the ICMJE uniform disclosure form, all authors declare the following:

Financial Relationships: All authors have declared that they have no financial relationships at present or within the previous three years with any organizations that might have an interest in the submitted work.

Other Relationships: All authors have declared that there are no other relationships or activities that could appear to have influenced the submitted work.

\section{AUTHORS CONTRIBUTIONS}

\begin{tabular}{|l|l|l|}
\hline Sr.\# & Author's Full Name & Intellectual Contribution to Paper in Terms of: \\
\hline 1. & Waqas Noor Chughtai & 1. $\quad$ Study design and methodology. \\
\hline 2. & Muhammad Adeel Razzaque & 2. $\quad$ Paper writing, referencing, and data calculations. \\
\hline 3. & Tanveer Ahmad & 3. $\quad$ Data collection and calculations \\
\hline 4. & Sumera Nighat & 4. $\quad$ Analysis of data and interpretation of results. \\
\hline 5. & Bashir Ahmad & 5. $\quad$ Literature review and manuscript writing. \\
\hline 6. & Muhammad Azhar Javed & 6. $\quad$ Analysis of data and quality insurer. \\
\hline
\end{tabular}

